\title{
Internet school for young scientists and students on optics, laser physics, and biophyics as a new approach for multidisciplinary continuing education
}

\section{Dmitry Agafonov, Valery Tuchin}

Dmitry N. Agafonov, Valery V. Tuchin, "Internet school for young scientists and students on optics, laser physics, and biophyics as a new approach for multidisciplinary continuing education," Proc. SPIE 4588, Seventh International Conference on Education and Training in Optics and Photonics, (28 May 2002); doi: 10.1117/12.468733

\section{SDIE Event: Education and Training in Optics and Photonics 2001, 2001,} Singapore, Singapore 
Invited Paper

\title{
Internet school for young scientists and students on optics, laser physics and biophysics as a new approach for multi-disciplinary continuing education
}

\author{
Dmitry N. Agafonov ${ }^{1}$ and Valery V. Tuchin \\ Saratov State University, Saratov, RU 410026
}

\begin{abstract}
The annual International school for young scientists and students on optics, laser physics and biophysics (Saratov Fall Meeting (SFM)) having five years experience in organization of a special Internet session is described. The technology of the Internet conference organizing as a new approach for distant and continuing education is discussed.
\end{abstract}

Keywords: Internet conference, distant education, multi-disciplinary approach, continuing education, optics, laser physics, optical biophysics, biomedical optics

\section{INTRODUCTION}

To identify the various local issues and solutions that can be emulated globally through various networking possibilities the advantages and problems of the Internet Conference organizing as a global educational event should discussed.

The annual Multidisciplinary International School for Young Scientists and Students on Optics, Laser Physics and Biophysics (Saratov Fall Meeting (SFM)) has five years experience in organization of a special Internet session. ${ }^{1-9}$ A wide range of modern problems of fundamental and applied optics, laser physics, photonics and biomedical optics is usually under discussion. Last year SFM has contained five International Workshops on Optical Technologies in Biophysics and Medicine; Coherent Optics of Ordered and Random Media; Laser Physics and Photonics; Spectroscopy and Molecular Modeling; and Modern Optics (for teachers and secondary school students). The main organizer of Saratov Fall Meetings is Saratov State University.

In this paper we will discuss the technology of Internet Conference organizing, its advantages and problems.

\section{GENERAL DISCRIPTION}

The goal of the School and the Workshops is to involve young researches and students in the field of recent developments and applications of laser and optical technologies in medicine and biology, coherent optics of random and ordered media, nonlinear dynamics of laser systems, laser spectroscopy and molecular modeling. The main attention was paid to discussion of fundamentals and general approaches of description of coherent, low-coherent, polarized, spatially and temporally modulated light interactions with inhomogeneous absorbing media, photonic crystals, tissue phantoms, and various biological tissues.

The Internet session is of great importance for such big countries as Russia and Former Soviet Union as well as for International community. The lack of travel funding, additional time spending for travel, rather high cost of a long distant travel and accommodation are the economical and organization reasons for creation of virtual conferences.

From the other hand, there is much easier for Program and Organizing Committees of the Meeting to recruit the worldrecognized experts for lecturing via Internet. For example, during last few years the following plenary lecturers have done excellent Internet presentations: Britton Chance (University of Pennsylvania, USA), James Fujimoto (MIT,

${ }^{1}$ Department of Physics, Saratov State University, 155, Moskovskaya str., Saratov, 410026, Russia; tel/office: +7 (8452) 51-46-93, fax: +7 (8452) 24-04-46; e-mail: aga@rsm.ru (DNA); tuchin@sgu.ru (VVT). 
USA), Steven Jacques (Oregon Medical Laser Center, USA), Alexander Oraevsky (University of Texas Medical Branch, USA), Lihong Wang (University of Texas, USA), Joseph Izatt (Case Western Reserve University, USA), David Boas (Massachusetts General Hospital, USA), Jun Uozumi (Hokkai-Gakuen University, Japan), Mark Brezinski (MIT, USA), and Nikolay Zheludev (University of Southmpton, UK).

The Internet session usually has a very good geography: participants from USA, Russia, Austria, Germany, UK, Poland, Slovakia, China, Italy, Ukraine, Belarus, Spain, the Netherlands, Japan and other countries have located their papers on the meeting website: http://optics.sgu.ru/SFM/, which was available during the meeting and is available for a few years after the meeting.

Professors and students who were not able to come to Saratov had a good opportunity to present their papers and to participate in discussions during this special session. Three-hour on-line Internet discussion of all presented on Internet session papers via chat moderated by Alexander Priezzhev (Moscow State University, Russia) were provided on each meeting. The facilities of Saratov University Internet Center allow for more than one hundred participants to take part concurrently in the discussion. Very important feature that discussion of an Internet paper can be done in more details and all papers can be discussed in a parallel mode. For example, plenary or invited lecturers have up to twenty questions and their written answers contain a lot of additional material. The main part of the presented Internet papers were and will be published as a few volumes of SPIE Proceedings. ${ }^{1-9}$

\section{TECHNOLOGY}

Discussing the model of the conference one can find two different types of top-level objects: interacting objects and informational objects (Fig.1). Committee, technicians, authors and audience (Fig.1a) are the interacting parties of the conference activity. Participants deal with pieces of information, which can be categorized as shown in Fig. $1 \mathrm{~b}$.

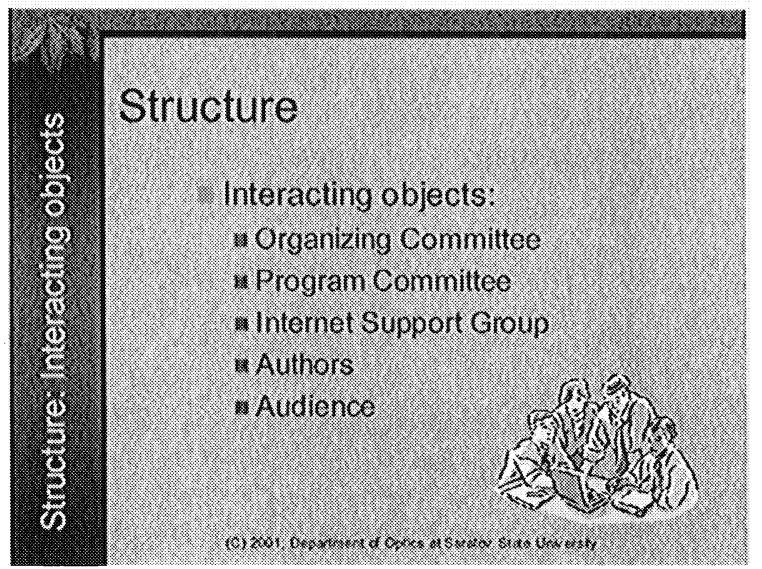

a)

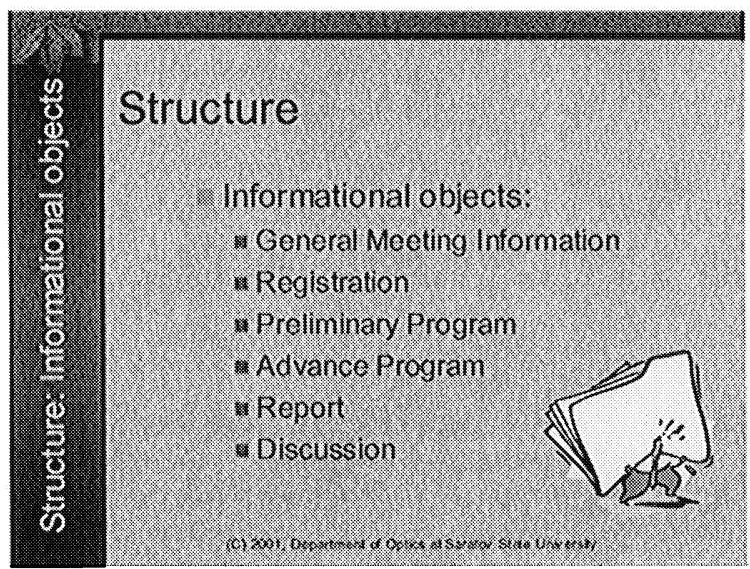

b)

Fig.1. Overview of the conference model: a) Interacting parties of the conference activity; b) Information objects which are sources or results of the activity.

Internet Conference is to employ newer and effective ways of communication for persons and groups. Internet gives the framework to build on-line systems to connect thousands of people together at one time. It is capable to handle all information flows required for successful conference organization.

The flow of conference process can be described as follows (Fig.2):

- The organizing committee develops and publishes via Internet general conference information: Call for papers, guidelines, etc.

- Potential authors receive this information worldwide through conference website or via personal contacts. 
- When author wishes to participate in the conference he/she makes registration and abstract submission at the conference website.

- Members of the program committee review submitted papers and complete the preliminary program.

- An author of the accepted paper prepares the Internet version of a report as recommended in the Conference guidelines and publishes it at the Conference website for public access.

- The Chair of the Conference basing on the preliminary program develops the advance program and also publishes it for public access.

- Then worldwide audience is able to join the Conference, the interested people are looking through contents, finding topics of interest, reading reports.

- On-line discussions is the way for authors to meet audience, to answer questions, to show the achievements, to exchange experience.

Note that Internet support group performs all technical support, including data flow control. Management of the data itself can be delegated to the committee secretaries through a set of simple interfaces.

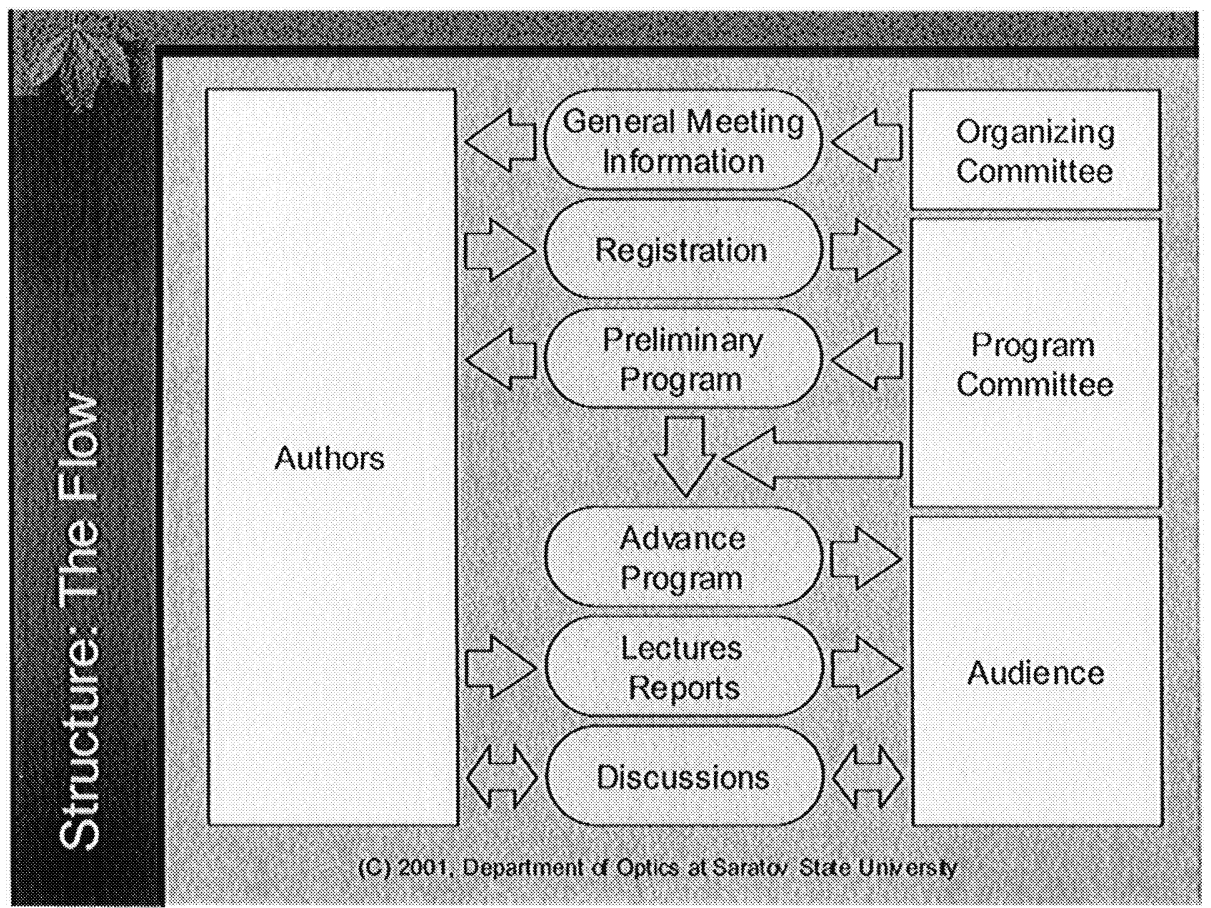

Fig.2. The flow-chat of the Conference process. The scheme describes the interaction in major stages from the beginning up to the closing of the Conference: explore the route using arrows from top to bottom of the scheme.

Discussing technical details of realization of the algorithm described above note the following key moments:

- Easy manageable information content: committee secretaries have to add, to update and to remove information located at the Conference website in order to hold information up-to-date and to inform visitors by recent news and events. The special software for providing of these tasks should be understandable and has user-friendly interface with reliable algorithm for handling of errors, which allow one to avoid loss or corruption of data.

- Advanced registration form: authors are to provide all information needed by the Organizing and Program Committees. Presenting author gives personal information, information about the paper, abstract and some optional information, which form four parts of the registration. Software provides strong data checking, which prevents submission of incomplete or wrong data and also have clear way to eliminate and correct possible errors in the registration form. 
- Preliminary and advanced program: Program Committee accumulates registration information and releases preliminary program and then transforms it into the advance program including information on the time-table of the conference. This process can be automated and software makes it easy to manage the information and allows for building of different views of content (with different sorting and filtering criteria).

- Reports and lectures on-line: several types of lectures/reports can be submitted: plenary lectures, invited lecture, report, etc. Usually, ones have limits in amount of information and form of presentation. Invited lecture can be longer and its author is allowed for using of different forms of presentation. Plenary lectures are presented at special Plenary Session. Thus the requirement for this type of report is to be maximally alike with normal oral report. One of such forms is "slideshow" with audio commentaries of an author, which are prepared and transferred to the site before Plenary Session.

- On-line discussions: discussion is one of the major parts of the Internet Conference. There are several ways to organize on-line discussions via Internet from videoconferencing to mailing lists. Ones are not preferable for the network bandwidth requirements other for their delayed interaction or strict requirements for discussion participants. One of the suitable ways is to organize discussion using "bulletin board" or "forum" layout. This layout allows to moderate questions, to invite people worldwide to join the discussion at their preferable time but still provide participants with ability to get answer from the author immediately if author is on-line at the same time during general discussion session.

Nowadays SFM employs most of these techniques to provide better quality of Internet part of the Conference: School and Workshops for Young Scientists and Students on Optics, Laser Physics and Biophysics (see http://optics.sgu.ru/SFM/). Examples of lectures and reports can be found in Fig.3:

a) "Strengths and weaknesses of various optical imaging techniques", Steven L. Jacques, Ph.D., Oregon Health and Science University, USA (SFM'01) - Plenary Lecture;

b) "Ultrasound-Mediated Biophotonic Imaging", Lihong Wang, Ph.D., Texas A\&M University (SFM'01) Plenary Lecture;

c) "Light scattering in turbid media: insights to optical imaging with single scattered and multiply scattered light”, Kostadinka Bizheva and David Boas, Nuclear Magnetic Resonance Center, Massachusetts General Hospital and Harvard Medical School (SFM2000) - Plenary Lecture;

d) "Computer Simulation of Light Propagation in a Multi-Layer Biological Tissue by Monte-Carlo Method", Eugeny P. Savchenko, Valery V. Tuchin, Saratov State University (SFM'99) - Report.

\section{CONCLUSION}

From year to year, the significance of Internet part of SFM increases due to the convenience of such form of the scientific information exchange and virtual learning (Fig.4).

Problems and suggestions:

1. At present the Internet resources in many Universities do not allow to provide on-line Plenary and Invited sessions of 10-12 hours of duration using novel network technologies (including video and audio broadcasting), that is why low-cost and effective technology presented in this paper seems to be attractive for distant education.

2. It is difficult to find optimal time-schedule for on-line discussion convenient for Far Eastern (Japan), European and Western (USA) countries.

3. Besides hard copies of Meeting Proceedings an electronic version (CD disc) should be issued and distributed.

\section{ACKNOWLEDGMENTS}

On behalf of SFM organizers and attendees we express our gratitude to all sponsoring organizations and programs that very effectively supported this meeting: first to SPIE Russian Chapter, and personally to Executive director, Dr. Edmund Akopov; then to Chernyshevsky Saratov State University; Russian Foundation for Basic Research (grants 9615-96389; 98-02-26126; 99-02-26125; 00-02-26132; 00-15-96667); Russian Federal Program "Integration," section 1.6 (grant \# 696.2); U.S. Civilian Research and Development Foundation for the Independent States of the Former Soviet Union (CRDF)(grant REC-006); Institute of Precision Mechanics and Control, Russian Academy of Sciences; TECHNOSERV-S, Ltd.; Almus, Ltd.; and Erudite - 96, Ltd. 

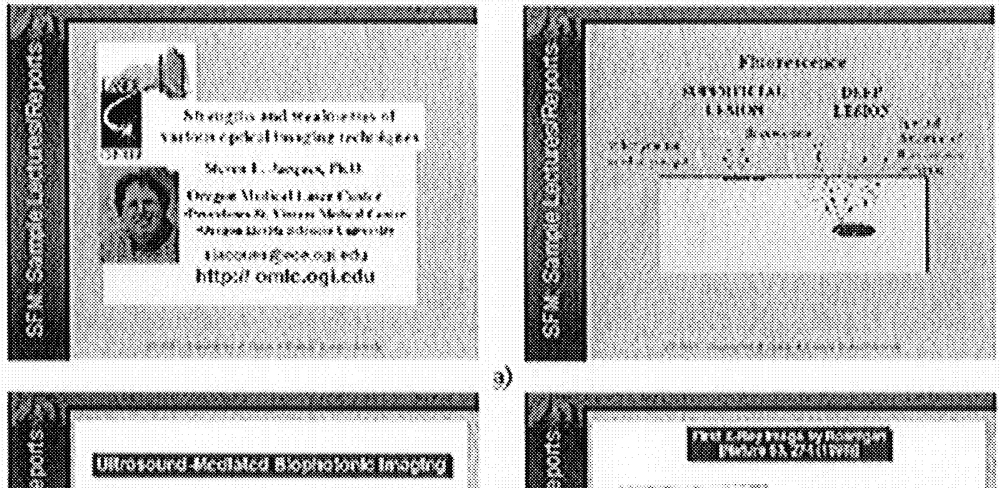

a)
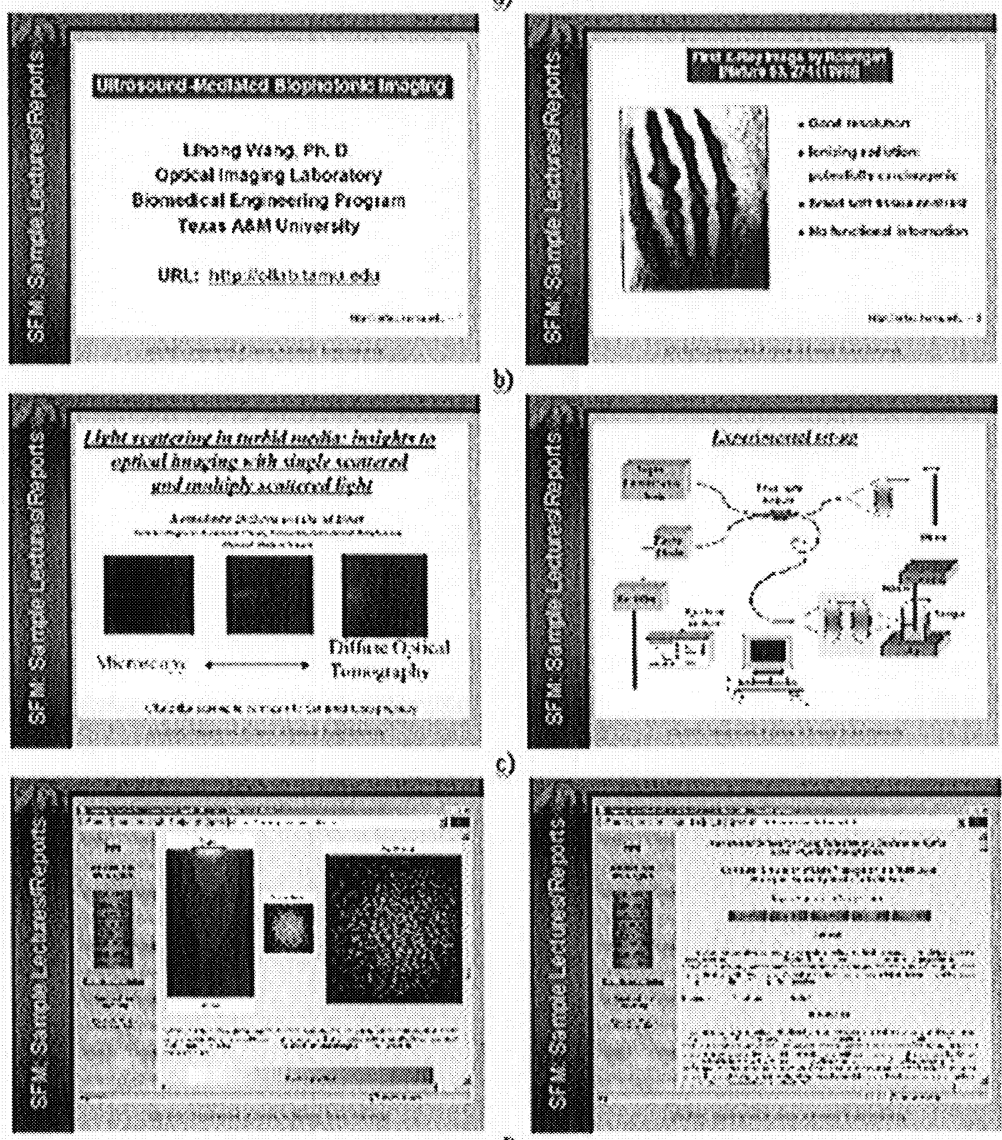

c)

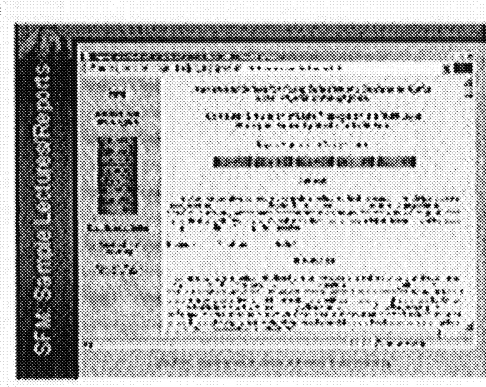

b)

Fig. 3. Examples of online lectures/reparts from SFM conference website. 


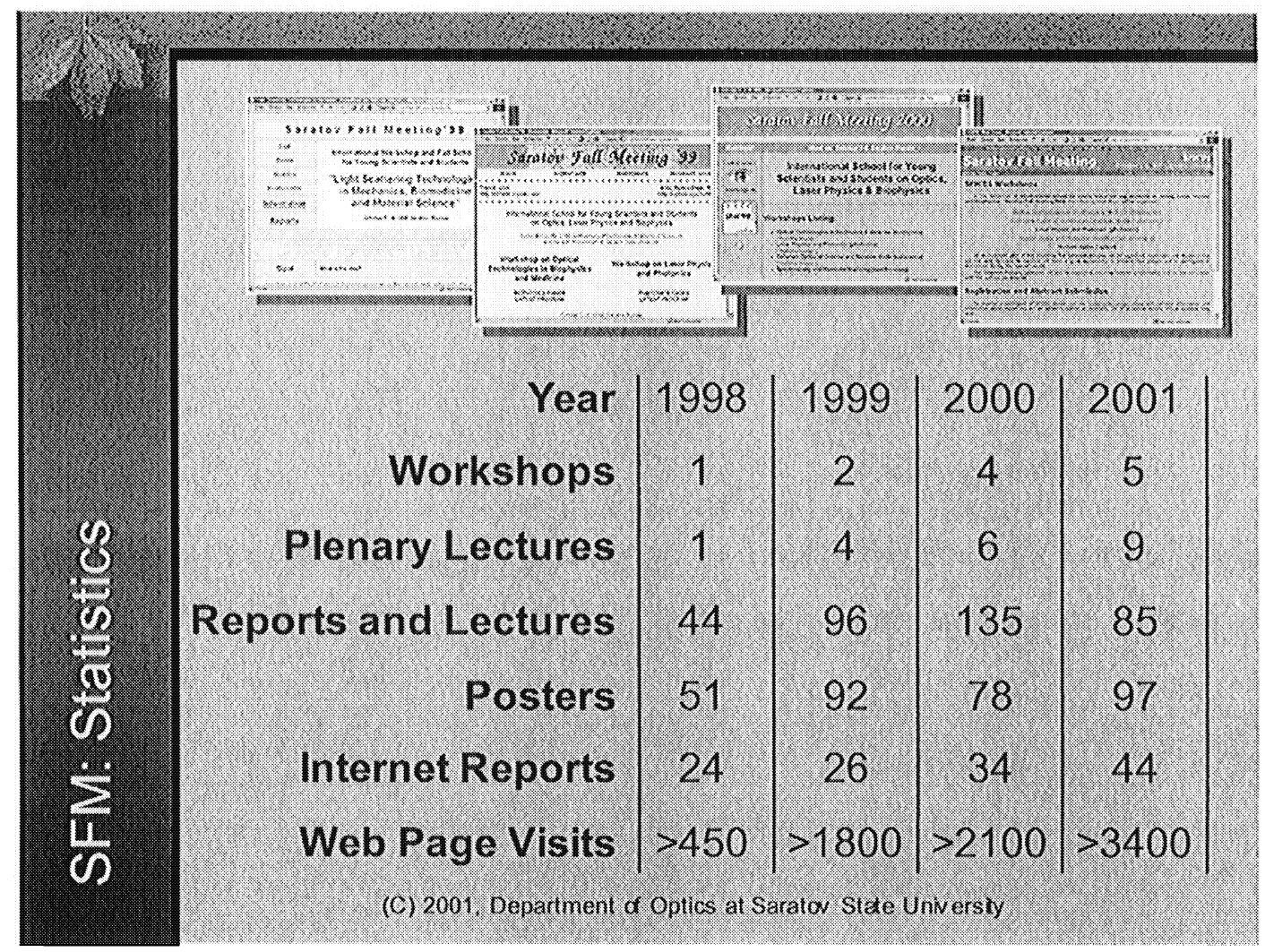

Fig.4. The statistics of SFM shows appreciable growth of importance and popularity of Internet session.

\section{REFERENCES}

1. V.V.Tuchin, V.P.Rayabukho, and D.A.Zimnyakov (Eds.), Saratov Fall Meeting: Light Scattering Technologies for Mechanics, Biomedicine, and Material Science, Proc. SPIE 3726, 1999, $617 \mathrm{p}$.

2. V.V.Tuchin, D.A.Zimnyakov, and A.B. Pravdin (Eds.), Saratov Fall Meeting: Optical Technologies in Biophysics and Medicine, Proc. SPIE 4001, 2000, $460 \mathrm{p}$.

3. V.L.Derbov, L. A.Melnikov, and L.M. Babkov (Eds.), Saratov Fall Meeting:Laser Physics and Photonics, Spectroscopy and Molecular Modeling, Proc. SPIE 4002, 2000, 300 p.

4. V.V.Tuchin (Ed.), Saratov Fall Meeting: Optical Technologies in Biophysics and Medicine II, Proc. SPIE 4241, 2001, $576 \mathrm{p}$.

5. D.A. Zimnykov (Ed.), Saratov Fall Meeting: Coherent Optics of Ordered and Random Media, Proc. SPIE 4242, 2001.

6. V.L.Derbov, L. A.Melnikov, and L.M. Babkov (Eds.), Saratov Fall Meeting: Laser Physics and Photonics, Spectroscopy and Molecular Modeling II, Proc. SPIE 4243, 2001.

7. D.A. Zimnykov (Ed.), Saratov Fall Meeting: Coherent Optics of Ordered and Random Media II, Proc. SPIE 4705, 2002.

8. V.L.Derbov, L. A.Melnikov, and L.M. Babkov (Eds.), Saratov Fall Meeting: Laser Physics and Photonics, Spectroscopy and Molecular Modeling III, Proc. SPIE 4706, 2002.

9. V.V.Tuchin (Ed.), Saratov Fall Meeting: Optical Technologies in Biophysics and Medicine III, Proc. SPIE 4707, 2002. 

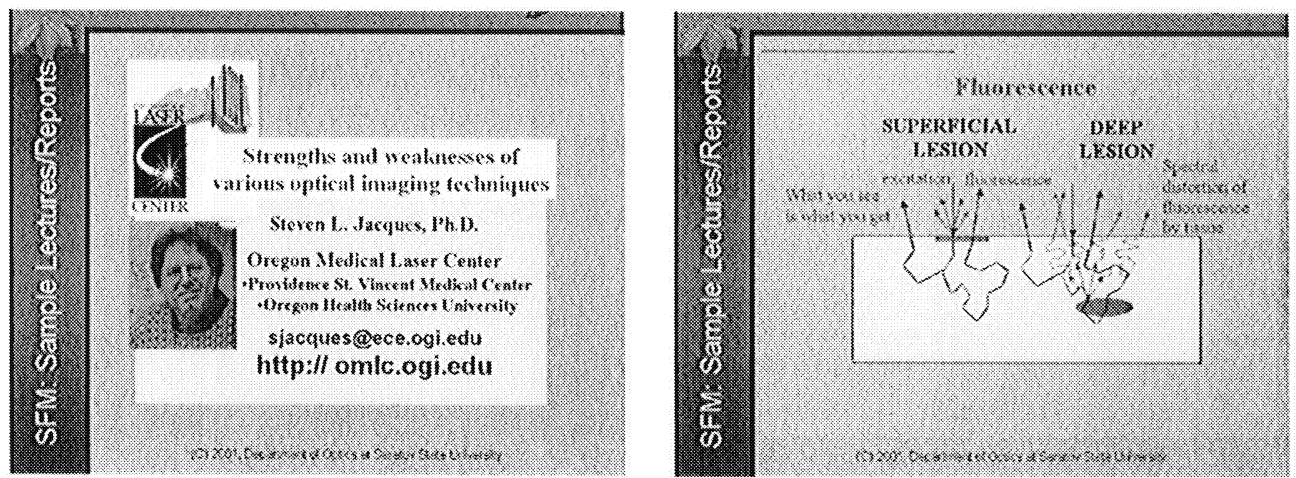

a)
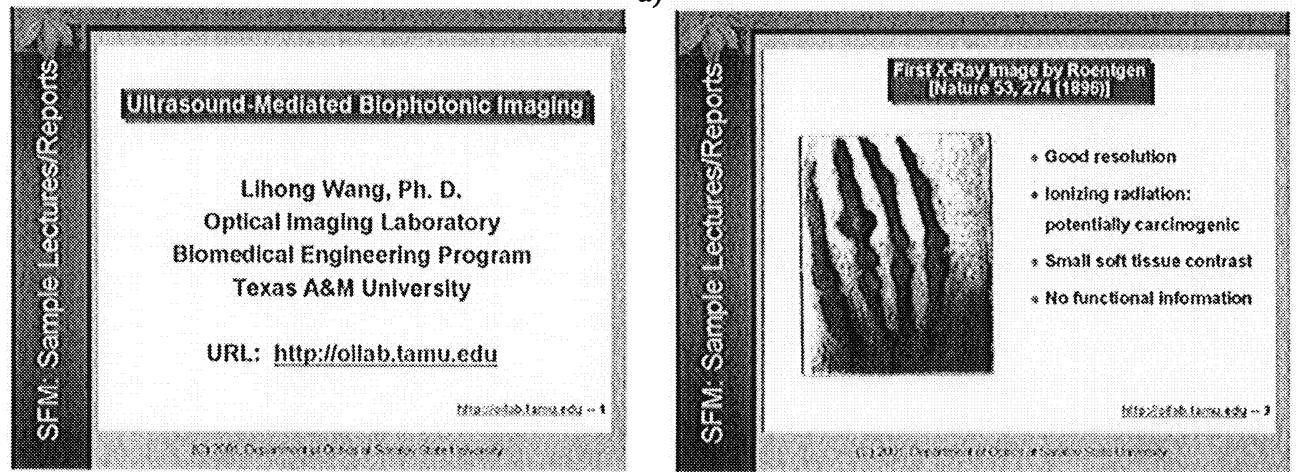

b)
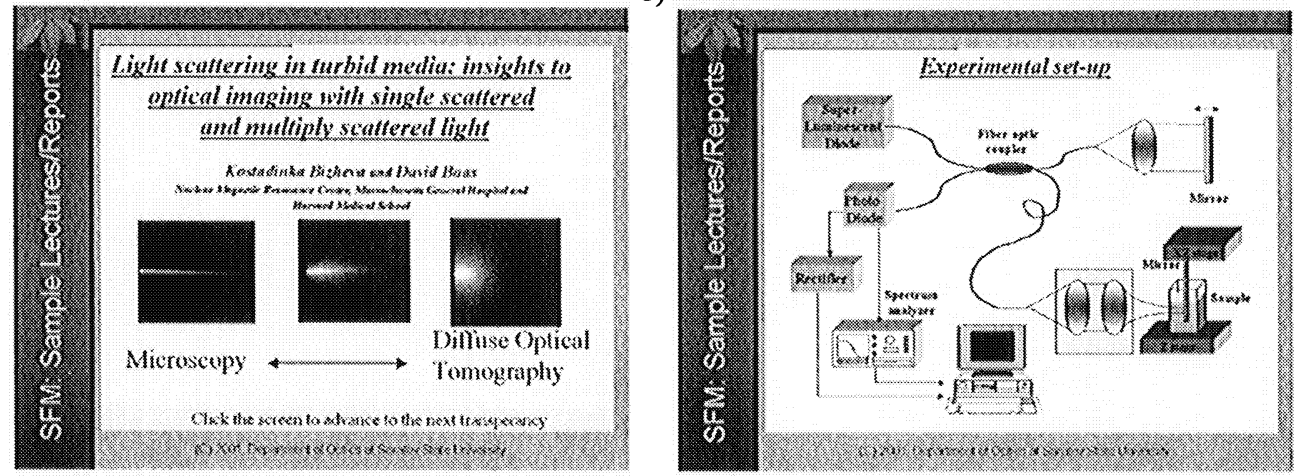

c)
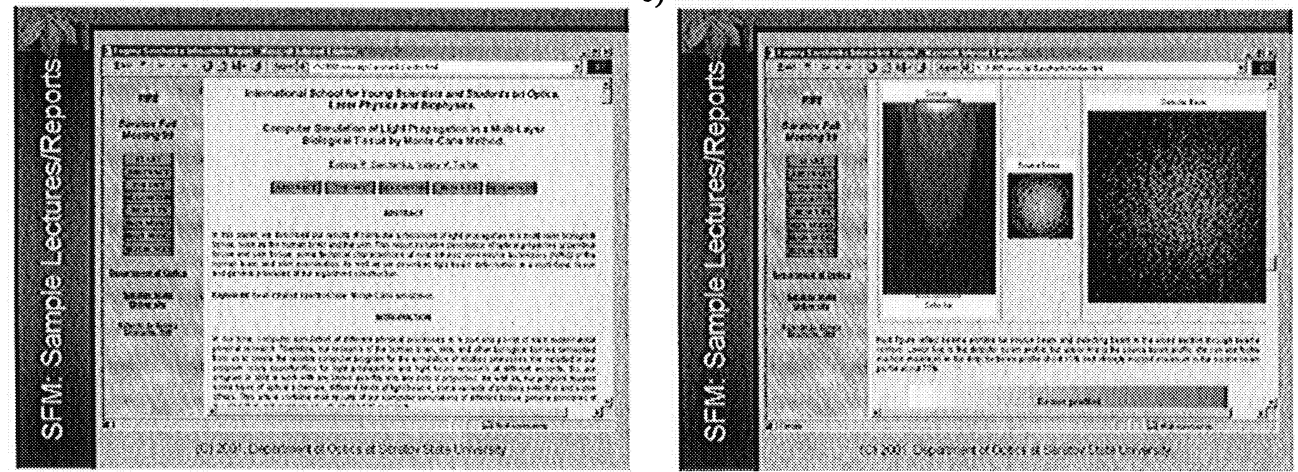

d)

Fig. 3. Examples of online lectures/reports from SFM conference website. 